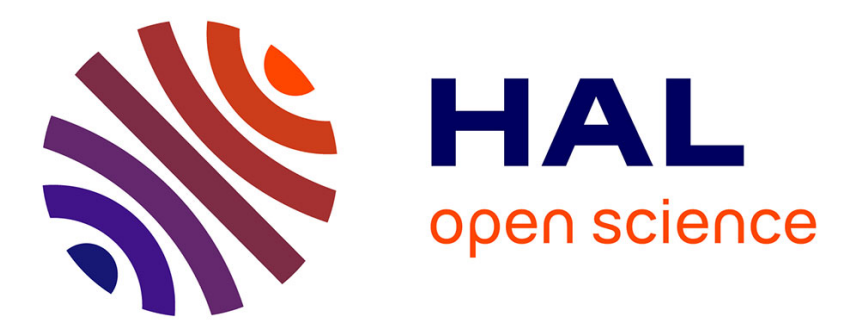

\title{
Surgically assisted rapid maxillary expansion for obstructive sleep apnea adult patients: our experience in 7 cases.
}

\author{
Fabienne Carré, Xuân-lan Nguyen, Pascal Garrec, Bertrand Baujat, Jean
} Lacau St Guily, Boris Pételle

\section{To cite this version:}

Fabienne Carré, Xuân-lan Nguyen, Pascal Garrec, Bertrand Baujat, Jean Lacau St Guily, et al.. Surgically assisted rapid maxillary expansion for obstructive sleep apnea adult patients: our experience in 7 cases.. Clinical Otolaryngology, 2021, 10.1111/coa.13816 . hal-03260313

\section{HAL Id: hal-03260313 https://hal.sorbonne-universite.fr/hal-03260313}

Submitted on 14 Jun 2021

HAL is a multi-disciplinary open access archive for the deposit and dissemination of scientific research documents, whether they are published or not. The documents may come from teaching and research institutions in France or abroad, or from public or private research centers.
L'archive ouverte pluridisciplinaire HAL, est destinée au dépôt et à la diffusion de documents scientifiques de niveau recherche, publiés ou non, émanant des établissements d'enseignement et de recherche français ou étrangers, des laboratoires publics ou privés. 


\section{TITLE}

Surgically assisted rapid maxillary expansion for obstructive sleep apnea adult patients: our experience in 7 cases.

\section{$\underline{\text { Key Points: }}$}

1. Maxillomandibular advancement is the most effective surgery but does not consider transverse maxillary deficiency.

2. Surgically assisted rapid maxillary expansion in adults is an orthognathic current procedure of rising interest.

3. The search of a transverse maxillary deficiency is necessary in patients presenting with obstructive sleep apnea syndrome.

4. Therapeutic protocol needs to be established by a multidisciplinary team with an orthodontic approach.

5. After maxillary expansion, clinical and polysomnographic evaluation is needed to reassess maxillomandibular advancement surgery indication.

\section{Keywords:}

Surgically assisted rapid maxillary expansion

Obstructive sleep apnea

Apnea-Hypopnea Index

Epworth sleepiness scale 


\section{INTRODUCTION}

The highlighting of the role of craniofacial abnormalities in the development of obstructive sleep apnea syndrome has led to the development of different surgical procedures. Static craniofacial measures and dynamic airway collapse patterns are helpful to target surgical treatment ${ }^{1}$. Maxillomandibular advancement (MMA) is the most effective surgical treatment in adults with selected criteria. The indication must be weighted regarding risk-benefit balance. However, MMA does not take account of maxillary transverse deficiency (MTD). Rapid maxillary expansion (RME) in obstructive sleep apnea (OSA) in children has been well described in the literature with good results ${ }^{2}$. Few studies have evaluated the results of surgically assisted rapid maxillary expansion (SARME) in adults presenting with obstructive sleep apnea syndrome (OSAS). Twenty-five percent of patient presenting with a severe MTD have an OSAS $^{3}$.

\section{Objectives}

The aim of this study was to evaluate the efficacy of SARME in the surgical MMA management of OSAS adult patients presenting with MTD, analysing ventilatory events and daytime sleepiness.

\section{MATERIALS AND METHODS}

The Strengthening the Reporting of Observational Studies in Epidemiology (STROBE) guidelines for reporting observational studies were followed. 


\section{Ethical Considerations}

All patients signed an informed consent.

\section{Design and Settings}

We performed a retrospective chart review of all patients who benefited from maxillo-facial surgery for OSAS from 2001 to 2019 in the ENT department of a tertiary care center.

\section{Participants}

All patients were intolerant of nasal continuous positive airway pressure or refused long-term treatment. All patients operated on with SARME were included. They all underwent maxillary expansion along with orthodontic treatment. Orthodontic and surgical treatment plan was approved by a multidisciplinary medical committee specialised in somnology including, an ENT surgeon, orthodontists and sleep physicians. Orthodontic criteria to SARME surgery were: lack of coordination of the dental arches in the transverse direction linked endognathie, inverted premolar occlusion, ogival palate. All patients were operated on by the same experienced surgeon. Full polysomnography (PSG) was performed, within two months of surgery and at least two months thereafter.

\section{Main outcomes measures}

Variables examined were age, gender, malocclusion type, preoperative and postoperative body mass index (BMI), Epworth Sleepiness Scale (ESS) and apnea-hypopnea index (AHI) on PSG. Length of maxillary widening was measured clinically by inter-incisor space measurement.

We considered postoperative ESS $<10$ and postoperative AHI $<20$ with $\geq 50 \%$ decrease as SARME effectiveness criteria. 


\section{SARME procedure}

Before surgery, the distraction osteogenesis device was placed by the orthodontist on the first maxillary molar. It was activated 8 days after surgery to achieve $0,25 \mathrm{~mm}$ widening twice per day. After the completion of distraction, the distraction device was maintained in place for 6 months to allow bone consolidation. It was then removed by the orthodontist and the arch was orthodontically treated to prepare MMA procedure (Figure 1). Expansion process was complete when dental arches coaptation was obtained.

SARME procedure, under general anaesthesia, consisted in a limited osteotomy of Le Fort I level, with a median intermaxillary osteotomy between the central incisor teeth, without down-fracture. Intermaxillary mobilisation of the osteotomy was performed. Patients were observed overnight to monitor a possible bleeding.

\section{Analysis}

Descriptive and statistical analysis were performed. The paired Wilcoxon test was used for analysis of differences between paired data. P- values $<0.05$ were considered statistically significant. Statistical analysis was performed using GraphPad Prism 7 software.

\section{RESULTS}

Seven patients, four women and three men, benefited from SARME before pre-planned MMA surgery. They all presented a dento-skeletal class II with maxillary transverse deficiency. 


\subsection{Pre and postoperative patients data}

Data are reported in Table 1 . Mean age was $41 \pm 8.9$ years old. Mean maxillary expansion was $7.3 \pm 0.9 \mathrm{~mm}$. Pre and postoperative mean BMI were respectively $24.4 \pm 2.9$ and $23.9 \pm$ 3.4 .

Dental class was not modified by SARME.

\subsection{SARME effectiveness}

According to our descriptive effectiveness criteria (descriptive composite primary endpoint), SARME was efficient in two patients.

Five patients had a decreased AHI while one patient had an increased one. SARME reduced AHI by $31 \%$ (were $33.1 \pm 11.7 / \mathrm{h}$ to $23 \pm 21.3 / \mathrm{h}$ ).

Pre and postoperative mean ESS were respectively $12.4 \pm 3.0$ and $4.9 \pm 2.5$. After SARME, ESS decreased in all patients, with $60 \%$ of global diminution and normalised in 5 patients $(71 \%)$.

No minor or major surgical complications were encountered.

\subsection{Statistical analysis}

Postoperative ESS significatively decreased in patients who benefited from SARME ( $p=$ 0.022) while postoperative AHI decreased without reaching the significance threshold $(\mathrm{p}=$ 0.15) (Figure 2). There was no significant difference between pre and postoperative BMI ( $\mathrm{p}=$ $0.25)$.

\subsection{Post-SARME surgical management}


After SARME, therapeutic management was modified for $4 / 7$ patients. Two patients $\left(\mathrm{N}^{\circ} 1,2\right)$ had clinical and polysomnographic correction of their OSA by SARME. MMA had no further indication and surgery was cancelled.

Two other patients $\left(\mathrm{N}^{\circ} 6,7\right)$ decreased their ESS score and IAH and treatment plan was modified: mandibular sagittal split osteotomy was realised instead of MMA.

The indication of MMA was maintained for 3 patients $\left(N^{\circ} 3,4,5\right)$. Two of them benefited from postoperative MMA surgery PSG. Patient 3 normalised AHI and ESS (AHI = 3 and ESS =2). Patient 4 showed AHI improvement but no normalization $(\mathrm{AHI}=26)$.

\section{DISCUSSION}

\subsection{Key findings}

SARME is a current and safe procedure in orthognatic surgery. In case of maxillofacial surgical treatment of OSA, MTD should be analysed and considered. SARME procedure can improve SAOS and modified surgical decision. In selected patients, SARME can avoid MMA for a sagittal mandible advancement with same benefit concerning OSAS results.

\subsection{Strengths of the study}

Our study underlines the importance of the transversal dimension in the management of OSA in adults. Few studies have focused on the interest of maxillary expansion in OSA adults. Our study is the first to evaluate the effect of SARME on OSA in a pre-planned MMA surgery. It demonstrates the interest of a step by step strategy in orthognathic surgery for OSAS.

\subsection{Comparison with other studies}


Benefits of RME in children have been well studied ${ }^{4}$. This technique, which does not require surgery in children, has a significant effect on OSA and improves AHI, decreasing nasal resistance and increasing oropharyngeal space.

Palmisano et al. reported the first case of OSA treatment by SARME procedure ${ }^{5}$. Cistulli et al. confirmed these results on 10 patients with a decrease of $63,2 \%$ in postoperative AHI ${ }^{6} .$. It is interesting to note that the patient with the most severe OSA of this series (AHI 43/h) had no improvement in AHI. We observe a similar situation in our study with the highest preoperative AHI patient (AHI 54/h).

Bach et al. showed in a prospective study of 7 OSA adults that maxillary expansion significantly decreased AHI of $51 \%^{3}$. These two cohorts had lower preoperative AHI (respectively $19 \pm 4 / \mathrm{h}$ and $11 \pm 5 / \mathrm{h}$ ) than patients in our series $(33 \pm 12 / \mathrm{h})^{3,6}$.

Vinha et al. presented a prospective cohort of 16 patients with preoperative comparable data to our cohort according to age, BMI and AHI. SARME significantly decreased AHI of 56\% and ESS of $42 \%^{7}$.

Liu et al. reported a significant decrease of AHI, ESS and oxygen desaturation index associated with a significative enlargement of the antero-posterior nasal widths in 20 patients treated with a distraction osteogenesis maxillary expansion technique ${ }^{8}$.

In a study on 33 patients who benefited from endoscopically-assisted surgical expansion for OSAS, Li et al. observed $88 \%$ of patients presenting significant improvement with $\geq 50 \%$ reduction in AHI and reduction of ESS score ${ }^{9}$. These patients had comparable preoperative AHI and BMI to our series, but were on average 10 years younger.

This current literature promotes SARME as a surgical safe way to improve AHI ${ }^{10}$. Our results consolidate these data. Severe OSAS associated with high BMI or advanced age could be negative prognostic factors to SARME effectiveness. 


\subsection{Clinical applicability of the study}

SARME procedure is effective in a significant number of patients. Selection criteria are needed to be explored. It is necessary to reassess patients after maxillary expansion, using ESS and PSG, before MMA surgery.

SARME could reduce the mandibular advancement length needed to correct OSA and would decrease pain, length of hospital stay as well as potential complications such as nerve injury and delayed bone healing. SARME could also be useful reducing nasal resistance and facilitate myofunctional therapy. In this way, it would be interesting to measure nasal resistances before and after SARME. The improvement of nasal resistances could explain the improvement of ESS in patients without decrease of AHI in our study.

Prospective studies are needed to confirm these results and precise positive and negative prognostic factors of OSA surgical treatment by SARME.

\section{CONCLUSION}

SARME is an effective technique for OSA patients with MTD. This opens up a less invasive therapeutic option and strengthens the place of SARME in a planned orthodontic-surgical treatment protocol.

MMA remains the most effective multi-level surgical option for selected OSA patients, but correction of MTD is gaining more attention. It is interesting to look for MTD in patients presenting with OSA eligible for MMA. 


\section{REFERENCES}

1 Liu S.Y.-C., Huon L.-K., Lo M.-T., et al. (2016) Static craniofacial measurements and dynamic airway collapse patterns associated with severe obstructive sleep apnoea: a sleep MRI study. Clinical Otolaryngology 41, 700-706.

2 Awad M., Gouveia C., Zaghi S., et al. (2019) Changing practice: Trends in skeletal surgery for obstructive sleep apnea. J Craniomaxillofac Surg 47, 1185-1189.

3 Bach N., Tuomilehto H., Gauthier C., et al. (2013) The effect of surgically assisted rapid maxillary expansion on sleep architecture: an exploratory risk study in healthy young adults. J Oral Rehabil 40, 818-825.

4 Vale F., Albergaria M., Carrilho E., et al. (2017) Efficacy of Rapid Maxillary Expansion in the Treatment of Obstructive Sleep Apnea Syndrome: A Systematic Review With Meta-analysis. Journal of Evidence Based Dental Practice 17, 159-168.

5 Palmisano R.G., Wilcox I., Sullivan C.E., et al. (1996) Treatment of snoring and obstructive sleep apnoea by rapid maxillary expansion. Aust N Z J Med 26, 428-429.

6 Cistulli P.A., Palmisano R.G. \& Poole M.D. (1998) Treatment of obstructive sleep apnea syndrome by rapid maxillary expansion. Sleep 21, 831-835. 
7 Vinha P.P., Eckeli A.L., Faria A.C., et al. (2016) Effects of surgically assisted rapid maxillary expansion on obstructive sleep apnea and daytime sleepiness. Sleep Breath 20 , $501-508$.

8 Liu S.Y.-C., Guilleminault C., Huon L.-K., et al. (2017) Distraction Osteogenesis Maxillary Expansion (DOME) for Adult Obstructive Sleep Apnea Patients with High Arched Palate. Otolaryngol Head Neck Surg 157, 345-348.

9 Li K., Quo S. \& Guilleminault C. (2019) Endoscopically-assisted surgical expansion (EASE) for the treatment of obstructive sleep apnea. Sleep Med 60, 53-59.

10 Abdullatif J., Certal V., Zaghi S., et al. (2016) Maxillary expansion and maxillomandibular expansion for adult OSA: A systematic review and meta-analysis. $J$ Craniomaxillofac Surg 44, 574-578.

\section{DATA AVAILIBILITY STATEMENT}

Data available on request from the authors.

The data that support the findings of this study are available from the corresponding author upon reasonable request.

Corresponding author should be requested to access the data 


\section{$\underline{\text { Table } 1}$}

Patients data before and after surgically assisted rapid maxillary expansion.

\begin{tabular}{|c|c|c|c|c|c|c|c|c|c|}
\hline $\begin{array}{c}\text { Patient } \\
\text { No. }\end{array}$ & $\begin{array}{c}\text { Age } \\
\text { (years) }\end{array}$ & Sex & PreBMI & PostBMI & PreESS & PostESS & PreAHI & PostAHI & $\begin{array}{c}\text { Maxillary } \\
\text { Expansion } \\
\text { (mm) }\end{array}$ \\
\hline $\mathbf{1}$ & 41 & F & 23 & 23 & 6 & 3 & 27 & 7 & 8 \\
\hline $\mathbf{2}$ & 26 & M & 22 & 21 & 13 & 7 & 27 & 7 & 8 \\
\hline $\mathbf{3}$ & 54 & M & 23 & 21 & 12 & 6 & 54 & 63 & 6 \\
\hline $\mathbf{4}$ & 46 & F & 28 & 28 & 14 & 3 & 37 & - & 7 \\
\hline $\mathbf{5}$ & 34 & M & 22 & 21 & 13 & 9 & 40 & 28 & 8 \\
\hline $\mathbf{6}$ & 43 & F & 24 & 24 & 14 & 2 & 18 & 12 & 6 \\
\hline $\mathbf{7}$ & 43 & F & 29 & 29 & 15 & 4 & 29 & 21 & 8 \\
\hline
\end{tabular}

BMI: body mass index; ESS: Epworth sleepiness scale; - : data missing. 


\section{Figure 1}

Surgically assisted rapid maxillary expansion (SARME) of patient 1.

a.

b.

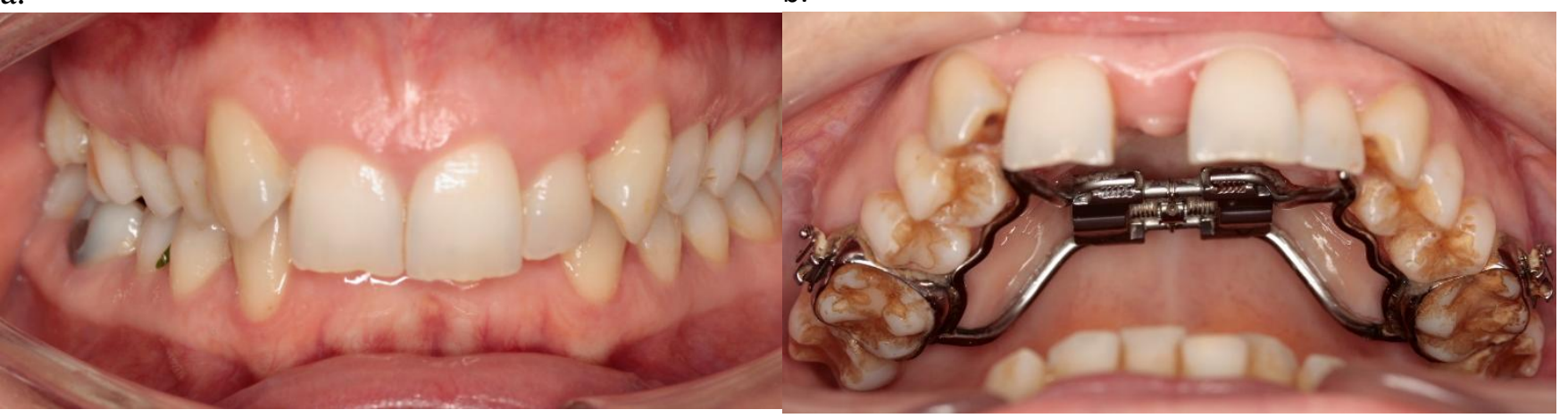

C.

d.

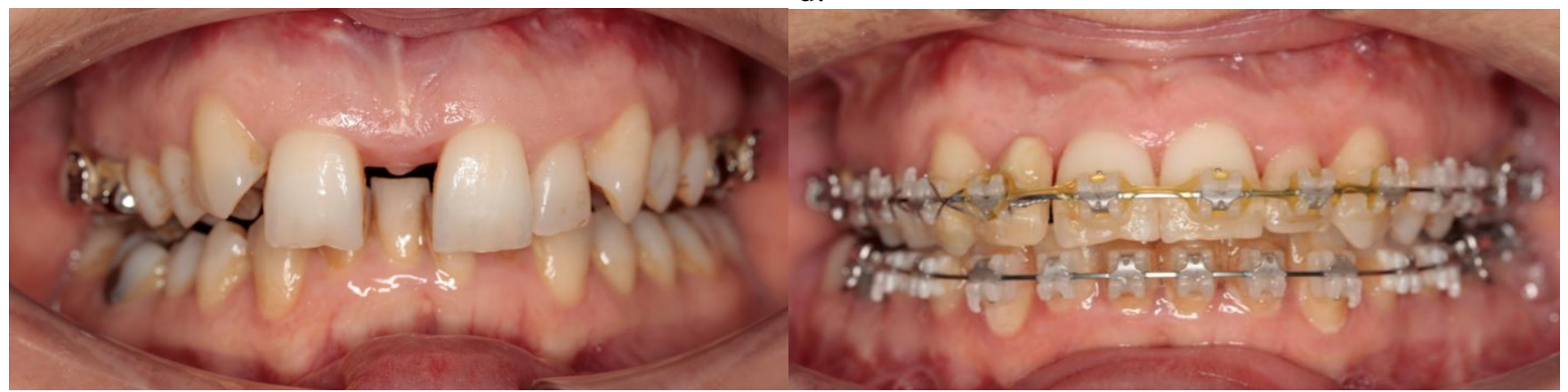

a. Pre-SARME maxillary transverse deficiency with bilateral posterior crossbite; $b$. expander in place; c. post-SARME; d. end of orthodontic treatment. 


\section{Figure 2.}

ESS before and after surgically assisted rapid maxillary expansion.

A.

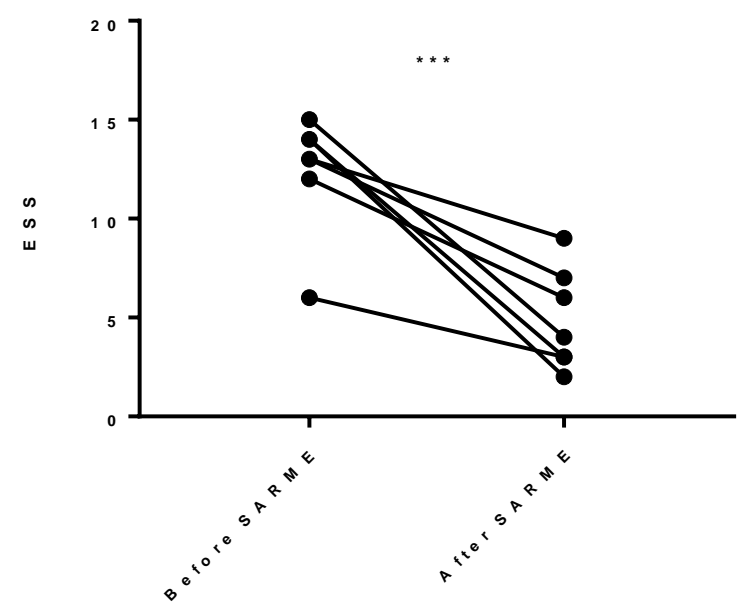

B.

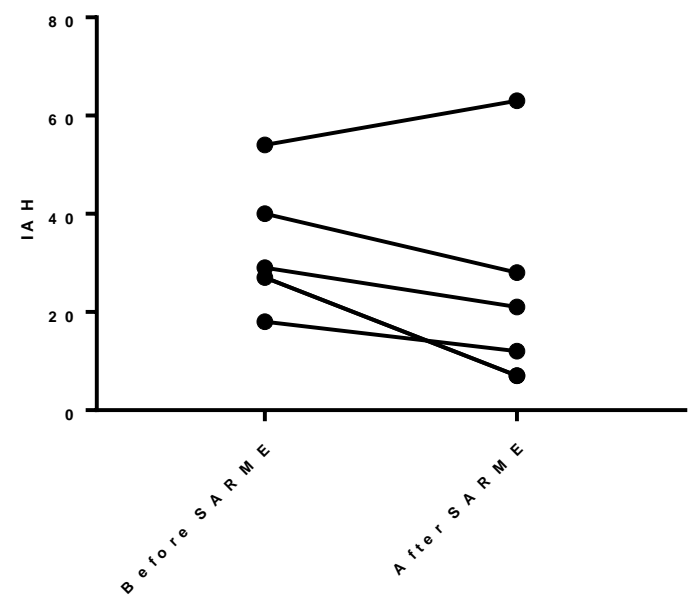

A. ESS before and after SARME in 7 patients $(* * *: p<0.05)$; B. AHI before and after SARME in 6 patients. Two patients had identical pre and postoperative AHI. 